Fabrice Vallée

Arnaud Mari

Anders Perner

Benoît Vallet

\section{Combined analysis of cardiac output and CVP changes remains the best way to titrate fluid administration in shocked patients}

Received: 1 February 2010

Accepted: 19 February 2010

Published online: 11 March 2010

(C) Copyright jointly held by Springer and ESICM 2010

This editorial refers to the article available at:

doi:10.1007/s00134-010-1755-2.

\section{F. Vallée $(\bowtie)$}

Réanimation Chirurgicale et Laboratoire de Recherche du Département d'Anesthésie- Réanimation (EA 322 Université Paris 7 Denis Diderot), Hôpital Lariboisière, Paris, France e-mail: vallee.fabrice@gmail.com

A. Mari

Pôle Anesthésie et Réanimation, Unité de Réanimation Polyvalente de Purpan, Université Paul Sabatier, GRCB 48, Toulouse, France

\section{A. Perner}

Department of Intensive Care, Rigshospitalet,

University of Copenhagen, Copenhagen, Denmark

B. Vallet

Anesthésie et Réanimation, CHU, Univ Lille Nord de France, 59000 Lille, France

Predicting fluid responsiveness is a topic of major interest. The passive leg raising (PLR) manoeuvre has been recently proposed and tested [1-8]. PLR is based on the principle that it can induce an abrupt increase in venous return secondary to auto-transfusion of peripheral blood from capacitive veins of the lower part of the body [9]. The attractiveness of PLR relates to the apparent simplicity of its physiology, but it presents some limitations $[5,6]$. In particular, the increase in preload is not predictable and may be insufficient to challenge the right cardiac function curve $[1,2,6]$. Also, the definitive technique to perform PLR-i.e., supine (PLR SUPINE $_{\text {) }}$ or semi-recumbent (PLR SEMIREC $)$-remains a matter of debate $[1,5,6,9]$.

In the present issue, Lakhal et al. [10] present the results of a multicenter study testing the predictive value of PLR for fluid responsiveness. They used thermodilution techniques to assess cardiac output (CO) changes during PLR (PLR-CO) and arterial pulse pressure (PP) changes during PLR (PLR-PP) as a surrogate for stroke volume (SV) [1, 2]. Lakhal et al. described a physiological approach to the problem of random effect of preload induced by PLR: cardiac preload was assumed to be increased during PLR if central venous pressure (CVP) increased $\geq 2 \mathrm{mmHg}$.

The main results are interesting and somewhat conclusive. Lakhal et al. demonstrated that predictive performance of PLR-CO was acceptable in the whole population as evidenced by the area under the ROC curve [AUC: 0.89 (0.81-0.94)], which confirmed previous findings $[2,7,8]$. But the performance of its surrogate PLR-PP was clinically inconsistent as already suggested $[2,8]$. Therefore, generalised use of PLR-PP as a marker of SV change induced by PLR cannot be supported [10]. Although only half of the included patients increased $\geq 2 \mathrm{mmHg}$ in CVP during PLR, the PLR-PP test performed better among these patients than in the overall population [AUC: $0.91(0.79-0.97)]$. Importantly, 98\% of the fluid challenges were well tolerated and all gave definitive information about fluid responsiveness.

The PLR test described by Lakhal et al. may be less useful than hoped for. Indeed, the proposed PLR-PP could be depicted as follows: (1) To detect an eligible patient within the whole ICU population (free of cardiac arrhythmias and deeply sedated). (2) To analyse CVP correctly as recommended [11]. (3) To perform PLR by leg elevation to $45^{\circ}$. (3) While continuously checking possible adrenergic stimulation, to detect a CVP increase $\geq 2 \mathrm{mmHg}$. (4) And finally, if CVP increases, to measure the averaged $\mathrm{PP}$ in order to minimise respiratory related variation. 
These practical aspects must be kept in mind before implementing these results in daily practice. However, the PLR manoeuvre used in this study (PLR SUPINE ) is controversial $[5,6,9]$. Instead, PLR SEMIREC $_{\text {may be used to reduce }}$ adrenergic and nociceptive stimulation and to increase the venous return induced by PLR [6].

Only half of the selected population was accurately discriminated with PLR-PP. In this sub-population, the best cut off value was an $8 \%$ increase in PP compared to baseline. This represented an approximate change of $3.8 \mathrm{mmHg}$ in PP. This is small and close to the error of measurement experienced with the available pressure monitors. This practical point seems crucial, as even the results of the present study were physiologically interesting and statistically significant; this small $8 \%$ threshold could largely reduce the reproducibility and efficiency of the manoeuvre at bedside.

Preload modification was deduced by CVP course by testing the hypothesis that the cardiac function curve is challenged when CVP $\geq 2 \mathrm{mmHg}$ during PLR. A large increase in CVP can be at least explained by two different mechanisms: either end-diastolic ventricle volume increased without increase in stroke volume (flat part of Starling relationship) or end-diastolic ventricle volume failed to increase because the patient was already on the steep part of the pressure-volume relationship. Indeed, the right auricular pressure-volume relationship has a curvilinear shape. In its steep part, a small increase of volume produces a marked increase in pressure at high distending volume. In such a scenario (e.g. ARDS [12]), an increase in CVP could be associated with a critical cardiac preload reserve breaking-point and thus depressed volume responsiveness. This point was suggested in the study of Lakhal et al. by two times more nonresponsive patients in the CVP $\geq 2 \mathrm{mmHg}$ group. Hence the results of the present study underline again that assessment of CVP changes during fluid challenge (or PLR) is recommended both to detect increase in right heart preload and to assess the tolerance to fluid loading [13].

Finally, this study underscores that the characteristics of patients included in studies of fluid responsiveness remain conceptually questionable. Indeed, statistical significance of dynamic indices depends on the population screened and tends to be reduced in mixed large sized ICU populations [14-16]. From a physiological point of view, the quest of a test to suit every situation is in vain. Benefit from fluid responsiveness predictive tests may be mostly relevant when focused in risk patients such as hypoxemic or cardiac failure. In these pathophysiological situations, accuracy of predictive tests as PLR-PP remains to be validated. On the other hand, the good tolerance of volume expansion advocates again that a cautious fluid challenge, with coupled assessments of CO and CVP is a clinical acceptable option which makes sense most of the time to detect and correct hypovolemia [13]. In the future, assessment of volume responsiveness should not only deal with a macro-hemodynamics response, but should include attempts to predict global benefit from fluid taking into account the impact of fluid on pulmonary capillary hydrostatics, ventilation-perfusion relationships and tissue oxygenation $[17,18]$. Fluid response in itself needs probably to be conceptually enlarged and refined.

In summary, the results presented by Lakhal et al. of PLR-PP in the sub-group of patients who increased CVP $\geq 2 \mathrm{mmHg}$ during PLR are attractive but need to be confirmed, especially in high risk patients. As demonstrated by this study, a combined analysis of CVP and CO changes remains actually the best way to titrate fluid administration. In sedated patients with persistent shock invasiveness for a better diagnostics cannot be disputed.

\section{References}

1. Boulain T, Achard JM, Teboul JL Richard C, Perrotin D, Ginies G (2002) Changes in BP induced by passive leg raising predict response to fluid loading in critically ill patients. Chest 121:1245-1252

2. Monnet X, Rienzo M, Osman D, Anguel N, Richard C, Pinsky MR, Teboul JL (2006) Passive leg raising predicts fluid responsiveness in the critically ill. Crit Care Med 34:14021407

3. Lafanechere A, Pene F, Goulenok C, Delahaye A, Mallet V, Choukroun G, Chiche JD, Mira JP, Cariou A (2006) Changes in aortic blood flow induced by passive leg raising predict fluid responsiveness in critically ill patients. Crit Care 10:R132
4. Maizel J, Airapetian N, Lorne E, Tribouilloy C, Massy Z, Slama M (2007) Diagnosis of central hypovolemia by using passive leg raising. Intensive Care Med 33:11331138

5. Caille V, Jabot J, Belliard G, Charron C, Jardin F, Vieillard-Baron A (2008) Hemodynamic effects of passive leg raising: an echocardiographic study in patients with shock. Intensive Care Med 34:1239-1245

6. Jabot J, Teboul JL, Richard C, Monnet X (2009) Passive leg raising for predicting fluid responsiveness: importance of the postural change. Intensive Care Med 35:85-90
7. Preau S, Saulnier F, Dewavrin F, Durocher A, Chagnon JL (2010) Passive leg raising is predictive of fluid responsiveness in spontaneously breathing patients with severe sepsis or acute pancreatitis. Crit Care Med 38:819-825

8. Thiel SW, Kollef MH, Isakow W (2009) Non-invasive stroke volume measurement and passive leg raising predict volume responsiveness in medical ICU patients: an observational cohort study. Crit Care 13:R111

9. Monnet X, Teboul JL (2008) Passive leg raising. Intensive Care Med 34:659663 
10. Lakhal K, Ehrmann S, Runge I, Benzekri-Lefèvre D, Legras A, Dequin $\mathrm{P}$, Mercier E, Wolff M, Régnier B, Boulain T (2010) Central venous pressure measurements improve the accuracy of leg raising-induced change in pulse pressure to predict fluid responsiveness. Intensive Care Med. doi:10.1007/s00134-010-1755-2

11. Magder S (2006) Central venous pressure monitoring. Curr Opin Crit Care 12:219-227

12. Vieillard-Baron A, Schmitt JM, Augarde R, Fellahi JL, Prin S, Page B, Beauchet A, Jardin F (2001) Acute cor pulmonale in acute respiratory distress syndrome submitted to protective ventilation: incidence, clinical implications, and prognosis. Crit Care Med 29:1551-1555
13. Vincent JL, Weil MH (2006) Fluid challenge revisited. Crit Care Med 34:1333-1337

14. De Backer D, Heenen S, Piagnerelli M, Koch M, Vincent JL (2005) Pulse pressure variations to predict fluid responsiveness: influence of tidal volume. Intensive Care Med 31:517523

15. Muller L, Louart G, Bousquet PJ, Candela D, Zoric L, de La Coussaye JE, Jaber S, Lefrant JY (2010) The influence of the airway driving pressure on pulsed pressure variation as a predictor of fluid responsiveness. Intensive care med 36:496-503
16. Vallee F, Richard JC, Mari A, Gallas T, Arsac E, Verlaan PS, Chousterman B, Samii K, Genestal M, Fourcade O (2009) Pulse pressure variations adjusted by alveolar driving pressure to assess fluid responsiveness. Intensive Care Med 35:1004-1010

17. Levy MM (2005) Pathophysiology of oxygen delivery in respiratory failure. Chest 128:547S-553S

18. Fougeres E, Teboul JL, Richard C, Osman D, Chemla D, Monnet X (2009) Hemodynamic impact of a positive endexpiratory pressure setting in acute respiratory distress syndrome: Importance of the volume status. Crit Care Med 38:802-807 